\title{
Emissions Reductions in Coal-Fired Home Heating Stoves Through the Use of Briquettes
}

\author{
Final Report \\ June 19, 1996
}

\section{RECEIVED \\ OCT 131998 \\ OSTI}

Work Performed Under Contract No.: DE-FC22-94PC94116

By

For

U.S. Department of Energy

Office of Fossil Energy

Federal Energy Technology Center

P.O. Box 880

Morgantown, West Virginia 26507-0880

Acurex Environmental Corporation

4915 Prospectus Drive

P. O. Box 13109

Research Triangle Park, North Carolina 27709

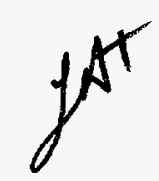

MASTER 


\section{Disclaimer}

This report was prepared as an account of work sponsored by an agency of the United States Government. Neither the United States Government nor any agency thereof, nor any of their employees, makes any warranty, express or implied, or assumes any legal liability or responsibility for the accuracy, completeness, or usefulness of any information, apparatus, product, or process disclosed, or represents that its use would not infringe privately owed rights. Reference herein to any specific commercial product, process, or service by trade name, trademark, manufacturer, or otherwise does not necessarily constitute or imply its endorsement, recommendation, or favoring by the United States Government or any agency thereof. The views and opinions of authors expressed herein do not necessarily state or reflect those of the United States Government or any agency thereof. 


\section{DISCLAIMER}

Portions of this document may be illegible in electronic image products. Images are produced from the best available original document. 


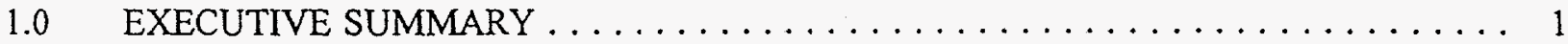

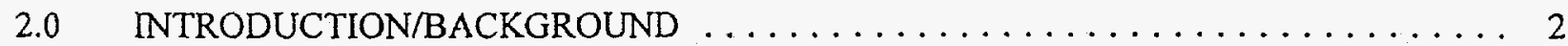

3.0 SPECIFIC OBJECTIVES OF THE PROJECT $\ldots \ldots \ldots \ldots \ldots \ldots \ldots \ldots \ldots \ldots$

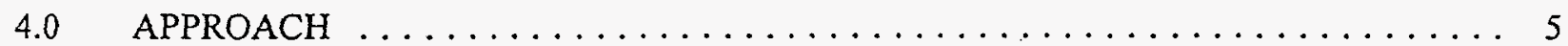

5.0 SPECIFIC SUCCESS CRITERIA FOR PHASE I $\ldots \ldots \ldots \ldots \ldots \ldots \ldots \ldots \ldots$

$6.0 \quad$ FULFILLMENT OF SUCCESS CRITERIA $\ldots \ldots \ldots \ldots \ldots \ldots \ldots \ldots \ldots$

$7.0 \quad$ DISCUSSION $\ldots \ldots \ldots \ldots \ldots \ldots \ldots \ldots \ldots \ldots \ldots \ldots \ldots \ldots$

7.1 Determination of a Briquette Formulation to Reduce Emissions

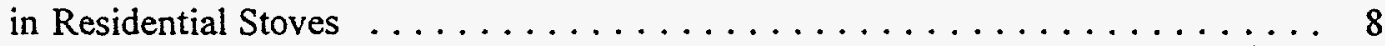

7.1 .1 Formulation Trials $\ldots \ldots \ldots \ldots \ldots \ldots \ldots \ldots \ldots \ldots \ldots \ldots$

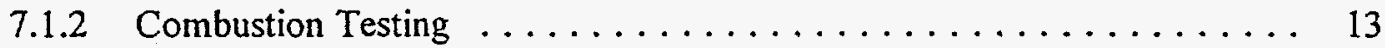

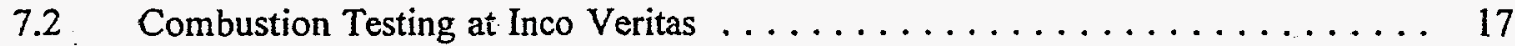

7.3 Combustion Testing at PEC Chrzanów District Heating Plant $\ldots \ldots \ldots \ldots \ldots$

7.5 . 1994 Heating Season Production to Support the With-Product . . . . . . . . . . 19

Market Testing ............................ 19

7.6 TCLP Testing of Combustion Residues . . . . . . . . . . . . . 19

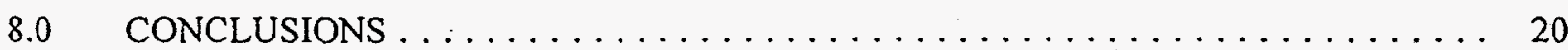




\section{LIST OF TABLES}

Table

Page

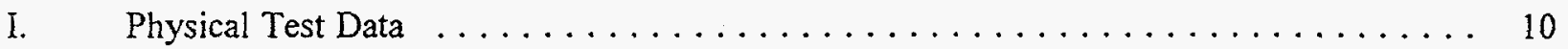

II. Tile Stove Combustion Results for Coal And Briquettes . . . . . . . . . . . 15 


\section{SECTION 1.0}

\section{EXECUTIVE SUMMARY}

This Final Technical Report for the Cooperative Agreement No. DE-FC22-94PC94116 summarizes technical achievements of the first year of the above cooperative agreement. Detailed technical data can be found in five Quarterly Technical Reports for the combined performance period from April 1, 1994 through June 30, 1995.

This report describes technical accomplishments of Phase I of the above cooperative agreement, which was the only phase completed. Initially planned Phase II has been deleted.

The purpose of Phase I was to optimize the clean burning coal briquette (Clean Fuel) formulation for Polish raw materials and to demonstrate the claimed pollution reducing benefits of its use in residential heating. Subsidiary goals were to test this fuel in larger scale facilities and to support the commercial tasks by producing Clean Fuel for use in the with-product market test. These goals were accomplished. Use of Clean Fuel in residential heating reduced particulate matter and total hydrocarbons emissions from ceramic home heating stoves compared to the combustion of premium chunk coal by 56 and 39 percent, respectively. It also results in higher thermal efficiency. An optimum formulation using Polish raw materials was determined and used in the production of Clean Fuel for the with-product market test. This fuel was also tested in a hand-stoked fixed grate boiler and 3 travelling grate boilers of varying size. 


\section{SECTION 2.0}

\section{INTRODUCTION/BACKGROUND}

The work performed was part of a program in the Support for Eastern European Democracy (SEED) Act of 1989 (P.L. 101-179). Following the guidance of this legislation, a U.S.-Poland Bilateral Steering Committee (BSC) was established to define the program. The BSC is directing a program of assistance to Poland that reduces air pollution in Kraków, Poland from about 1,300 boiler houses that provide heat for industrial, commercial, and residential applications, in addition to 100,000 small stoves for residential home heating. The 1,300 boiler houses and 100,000 residential home heating stoves in Kraków primarily use solid fossil fuels. They have been collectively called "low emissions sources" because of their low stack heights and the consequent low-level entry of flue gases into the ambient air.

In October 1991, a Memorandum of Understanding (MOU) was signed by the U.S. Department of Energy (DOE) and the Ministry of Environmental Protection, Natural Resources and Forestry of the Republic of Poland. The MOU is titled, "Collaboration on the Kraków Clean Fossil Fuels and Energy Efficiency Program, A Project of Elimination of Low Emission Sources in Kraków." This MOU described the cooperation that was being undertaken by the governments of the United States and the Republic of Poland to accomplish this program. Funding for the program was provided through the United States Agency for International Development (AID).

The purpose of the program is to encourage the formation of commercial ventures between U.S. and Polish firms to provide equipment and/or services to reduce pollution from low emissions 
sources in Kraków, Poland. These commercial ventures may take the form of contracts, joint ventures, partnerships, or any other commercially feasible arrangement that accomplishes the purpose of the statute. 
SECTION 3.0

\section{SPECIFIC OBJECTIVES OF THE PROJECT}

The overall objective of the cooperative agreement conducted by Acurex Environmental Corporation (Acurex Environmental) was to create a commercially successful venture that will market a low emission coal briquette for the residential heating market in Kraków.

Specific objectives of Phase I of the cooperative agreement were:

- Produce small quantities of Clean Fuel formulations

- Test the formulations in a home heating stove

- Conduct with-product market test

- Test Clean Fuel in hand-stoked fixed grate boiler

- Test Clean Fuel in travelling grate boilers

During Phase I, small quantities of the Clean Fuel product were manufactured and tested.

Clean Fuel is an environmentally friendly coal-based briquette with a proprietary binder. Five Polish coals and two Polish sources of binder material were tested to determine their amenability to fuel formation. Small-scale combustion tests in a residential stove were also performed during Phase I to determine the effectiveness of the Clean Fuel on emissions reductions. Sampling tests were also conducted on a hand-stoked fixed grate boiler and on three travelling grate boilers of different size burning Clean Fuel in lieu of coal. A preliminary engineering review of the plant was also performed. Construction of a new plant near Katowice to serve the Kraków market is being considered. 


\section{SECTION 4.0}

\section{APPROACH}

The approach taken during Phase I was to develop an optimum Clean Fuel formulation using Polish raw materials. This "optimum" was determined by the physical characteristics as well as the ability of the Clean Fuel to reduce particulate matter and organic emissions during combustion. This work was done at the briquetting and combustion laboratories of the Academy of Mining and Metallurgy (AGH) in Kraków. Once the optimum formulation was confirmed by these attestation experiments, larger quantities were manufactured at the Brikpol facility of Euromining Consulting, Inc. (EMC) in Bogdanka, Poland. These briquettes were used for marketing studies of the Kraków consumer market, as well as larger scale combustion tests at INCO Veritas (hand-stoked fixed grate boiler) and PEC at Chrzanów (travelling grate boilers). 
SECTION 5.0

SPECIFIC SUCCESS CRITERIA FOR PHASE I

As identified in Section 7.1 of the Phase I Project Management Plan, Update No. 1 dated September 1994, the technical success criteria were:

- Determination of a Clean Fuel formulation to reduce emissions in a residential stove

- Completion of combustion tests at the INCO Veritas boiler house

- Completion of combustion tests at the PEC Chrzanów district heating plant

- Production of Clean Fuel at Brikpol in quantity to support the with-product market survey, INCO Veritas testing, and PEC Chrzanów testing

- Production of the briquettes needed for with-product market testing during the 1994 heating season

- Completion of TCLP testing on combustion residues 


\section{SECTION 6.0}

\section{FULFILLMENT OF SUCCESS CRITERIA}

Accomplishments made during Phase I towards satisfying these goals:

- Experiments to determine Clean Fuel formulation which reduces stove emissions were successful. Significant reductions in carbon monoxide, particulate matter, and total hydrocarbons were observed. The specific criteria called for 50 percent reductions in particulate matter and organics. The particulate matter reduction was completely achieved with an actual reduction level of 56 percent. The organic reduction was only partially achieved with an actual reduction level of 36 percent. Carbon monoxide reduction was not predicted; an actual reduction of 41 percent was achieved.

- Combustion tests were performed at INCO Veritas and the PEC Chrzanów district heating plant.

- Quantity production of Clean Fuel was performed at EMC's Brikpol facility where sufficient quantities were manufactured to fully support the with-product market testing, combustion tests at INCO Veritas, and combustion tests at PEC Chrzanów.

- Production of Clean Fuel to support the with-product market testing within the 1994 heating season time frame was accomplished.

- TCLP testing is being performed; the data has not yet been received. 


\section{SECTION 7.0}

\section{DISCUSSION}

In this section we will discuss each of the six success criteria presented in Section 5 above. The first criteria is further subdivided between formulation trials and combustion testing.

\subsection{DETERMINATION OF A BRIQUETTE FORMULATION TO REDUCE EMISSIONS IN RESIDENTIAL STOVES}

\subsubsection{Formulation Trials}

Formulation experiments were conducted in the briquetting laboratory of Professor Drzymat a at the AGH in Kraków, Poland. Approximately 180 formulations were prepared to test the following eight parameters:

- Coal fines source

- Wujek Mine

- Brzeszcze Mine

- 0 to $4 \mathrm{~mm}$ coal fines size range

- 0 to $2 \mathrm{~mm}$ coal fines size range

- Siersza Mine

- Janina Mine

- Bogdanka Mine

- Binder source

- Baranów 
- Kraków

- Chrzanów

- Gliwice

- Bentonit

- Moisture content of the mass for briquetting as presented to press

- briquettes were prepared over the range of 3.8 to 37.5 percent moisture content

- Binder content

- 7.4 to 33 weight percent

- Briquette shape

- Saddle

- Drop

- Cylinder (cast technique only)

- Briquette size

- $3.0 \mathrm{~cm}$ by $2.9 \mathrm{~cm}$ by $1.3 \mathrm{~cm}$ ( $450-\mathrm{mm}$ diameter ring roll press)

- $7.2 \mathrm{~cm}$ by $7.0 \mathrm{~cm}$ by $3.0 \mathrm{~cm}(1,100-\mathrm{mm}$ diameter ring roll press)

- $3.0 \mathrm{~cm}$ diameter by $5.0 \mathrm{~cm}$ length (cast technique only)

- Formation technique

- Ring roll press

- Cast in forms

- Mixing technique

- Dry mix

- Wet mix

- Dry mix for 24 hours

- Wet mix for 24 hours 
Initial tests were performed on the 450 -mm ring roll press that is instrumented to monitor briquetting pressure. Each formulation was tested immediately after formation for the green drop shatter test. They were also tested 48 hours later for the aged drop shatter test. These tests were performed identically and differ only in the sample curing time prior to testing. Details of the drop shatter test may be found in our second quarterly report, period of July 1, 1994 to September 30 , 1994. Selected samples were also tested for compression strength; the details of this test may be found in our fourth quarterly report, period of January 1, 1995 to March 31, 1995. Wet sieve analysis was performed on several of the coal fine sources. The detailed results of briquetting pressure, green and aged drop shatter test percent survival, compression strength, and sieve analysis may be found in our quarterly reports and are not repeated here.

Table I presents the physical test data for several illustrative samples.

TABLE I. PHYSICAL TEST DATA

\begin{tabular}{|c|c|c|c||}
\hline No. & Fuel Formulation & $\begin{array}{c}\text { Aged Drop } \\
\text { Shatter Test (\%) }\end{array}$ & $\begin{array}{c}\text { Compression } \\
\text { Strength (N) }\end{array}$ \\
\hline 1 & $(\mathrm{Br}, \mathrm{K}, 14.3, \mathrm{~F}, \mathrm{Z}, 1100)$ & 95.9 & 478 \\
\hline 2 & $(\mathrm{Br}, \mathrm{K}, 14.3, \mathrm{Co}, \mathrm{Z}, 1100)$ & 79.4 & 214 \\
\hline 3 & $(\mathrm{Br}, \mathrm{C}, 14.3, \mathrm{~F}, \mathrm{Z}, 1100)$ & 76.2 & 262 \\
\hline 4 & $(\mathrm{Br}, \mathrm{C}, 14.3, \mathrm{Co}, \mathrm{Z}, 1100)$ & 70.7 & 171 \\
\hline 5 & $(\mathrm{Br}, \mathrm{G}, 14.3, \mathrm{Co}, \mathrm{S} 24,1100)$ & 78.9 & 203 \\
\hline 6 & $(\mathrm{Br}, \mathrm{G}, 14.3, \mathrm{Co}, \mathrm{Z}, 1100)$ & 76.1 & 212 \\
\hline 7 & $(\mathrm{Br}, \mathrm{C}, 14.3, \mathrm{~F}, \mathrm{Z}, \mathrm{Ca})$ & 82.3 & 297 \\
\hline 8 & $(\mathrm{Br}, \mathrm{G}, 14.3, \mathrm{Co}, \mathrm{S}, 450)$ & 51.5 & 65 \\
\hline 9 & $(\mathrm{Br}, \mathrm{G}, 14.3, \mathrm{Co}, \mathrm{Z}, 450)$ & 69.8 & 43 \\
\hline 10 & $(\mathrm{Br}, \mathrm{G}, 14.3, \mathrm{Co}, \mathrm{S} 24,450)$ & 81.1 & 67 \\
\hline 11 & $(\mathrm{~W}, \mathrm{~B}, 20, \mathrm{~F}, \mathrm{~S}, 450)$ & 78.5 & not performed \\
\hline 12 & $(\mathrm{~W}, \mathrm{~B}, 20, \mathrm{~F}, \mathrm{Z}, 450)$ & 93.2 & 92 \\
\hline
\end{tabular}

In this table the parenthetical phrase in the second column describes the sample preparation. "W" and "Br" refer to Wujek and Brzeszcze coal. Briquettes prepared from Brzeszcze coal used a washed fine material. " $B$ ", " $C$ ", " $G$ ", and " $K$ " refer to the binder sources from Baranów, Chrzanów, Gliwice, and Kraków, respectively. The number following the binder source code is the percent 
binder in the formulation. "F" and "Co" refer to fine (0 to $2 \mathrm{~mm})$ and coarse (0 to $4 \mathrm{~mm})$ cuts of the coal fines, respectively. "S", "S24", "Z", and "Z24" describe mixing technique:

- "S" refers to dry mixing of the clay and coal fines followed by water addition

- "S24" refers to dry mixing of the clay and coal followed by water addition with 24 hours of stabilization prior to the briquetting process

- " $Z$ " refers to a stepwise mixing process in which the binder is slurried with the water followed by admixture of the coal fines to the aqueous slurry

- "Z24" is similar to " $Z$ " followed by 24 hours of stabilization prior to the briquetting process

"Ca" refers to a briquette prepared by casting in forms. " $1,100 "$ and " $450 "$ refers to briquette formation on a ring roll press of $1,100 \mathrm{~mm}$ diameter and $450 \mathrm{~mm}$ diameter, respectively. A briquetted fuel product of adequate strength may be prepared using these materials and forming technologies. Comparison of compression strength for samples 1 to 6 with samples 8 to 12 in Table I demonstrates that the larger briquettes $(1,100 \mathrm{~mm}$ press $)$ are significantly stronger than small briquettes (450 mm press). This is demonstrated best by the sample pairs 5 versus 10 and 6 versus 9 . In each pair the only preparation variation is briquette size. The large briquettes have compression strengths that are three to five times that of the small briquette equivalent. We may also note that use of the wet mixing technique yields stronger briquettes than the dry mixing technique. This is demonstrated by comparison of drop shatter test results for sample pairs 11 versus 12 and 8 versus 9 . In both cases, the wet mixed sample provides superior results to the dry mixed samples. This difference, however, can be minimized through additional mixing time. This is demonstrated by comparison of drop shatter test results for sample sets 5 versus 6 and 10 versus 8 and 9 . Whereas samples 5 and 10 were dry mixed and would be expected to have lower drop shatter test results than samples 6 and 9, which were prepared by wet mixing, they actually are as strong as the wet mixed samples. The additional mixing time overcomes the dry mixing deficit. The use of 0 to $2 \mathrm{~mm}$ coal fines results in stronger briquettes 
than those prepared from 0 to $4 \mathrm{~mm}$ coal fines. This is demonstrated by comparison of the compression strength and drop shatter test results for sample pairs 1 versus 2 and 3 versus 4 . In both cases briquettes prepared from 0 to $2 \mathrm{~mm}$ coal fines are stronger by tests than those prepared from the coarser coal fines. In comparing the compression strength data, samples 1 and 3 are from 1.5 times to more than 2 times as strong as samples 2 and 4 . Finally, we may also note that preparation by the casting in forms technique also provides a briquetted fuel of adequate strength. Here, we can compare samples 7 and 3. Though sample 3 is significantly larger than the cast product, sample 7 compares favorably in terms of the drop shatter test results and compression strength.

The effect of raw material source was also found to be significant. Most binder sources were found to be capable of preparing briquettes of satisfactory strength at 14.3 percent binder content. However, Baranów binder was found to be unsatisfactory because of the presence of extraneous additives in this material. It required 20 percent Baranów binder content with Wüjek coal fines to achieve a compression strength of $92 \mathrm{~N}$. By contrast, only 14.3 percent of Chrzanów binder in Wujek fines provided a briquette 1.5 times as strong. Bentonit sourced binder proved capable of producing exceptionally strong briquettes even when prepared at low concentrations. The combination of 0 to $2 \mathrm{~mm}$ Brzeszcze fines with 7.4 percent Bentonit binder produced a compression strength of $110 \mathrm{~N}$. The numbers cited in this paragraph refer to small briquettes prepared on a $450 \mathrm{~mm}$ press. While satisfactory briquettes could be prepared from most of the coal fine sources, those from Janina proved the least satisfactory. These briquettes proved quite weak and easily broken even at 33 percent binder content. As noted earlier, coarse fines were also found to weaken the briquettes prepared from a given source. The sieve analysis provides at least part of the answer to the poor performance of the Janina based briquettes. It was found that the coarse ( 0 to $4 \mathrm{~mm}$ ) Brzeszcze fines and the Janina fines had the lowest content of the finest $(0$ to $0.16 \mathrm{~mm})$ fractions. The sieve analysis details may be found in our fourth quarterly report, January 1, 1995 to March 31, 1995 period. 


\subsubsection{Combustion Testing}

Twenty fuel samples were tested by the Combustion Laboratory of Dr. Szewczyk at the AGH in the instrumented tile stove. Two chunk coal samples were tested to provide baseline numbers in addition to the briquette samples. Stack gas sampling was accomplished through use of a dilution tunnel in a manner similar to United States Environmental Protection Agency (EPA) Method 5G. During combustion testing continuous emission monitors collected data for carbon dioxide, carbon monoxide, total hydrocarbons, sulfur dioxide, and oxides of nitrogen. The undiluted gas stream was monitored for carbon monoxide and temperature to permit calculation of the dilution ratio. Cyclone catch, filter, XAD-2 sorbent, and impinger samples were collected as a side-stream to the dilution tunnel.

Cyclone catch and filter samples were analyzed gravimetrically to determine particulate matter. Filter samples, XAD-2 sorbent samples, and impingers were analyzed to determine organic and inorganic materials. Detailed results and operational descriptions may be found in our second through fifth quarterly reports.

The earliest work was done with small briquettes prepared on the $450-\mathrm{mm}$ ring roll press. This was done because there was some concern that the briquettes would prove more difficult to ignite than chunk coal. It was believed that the higher surface area to volume ratio of the smaller briquettes would ameliorate such a condition. What was found was that there was no ignition difficulty with briquettes but that the emission results with the small briquettes were much more variable than those from the larger samples. Based upon this finding, work continued with large (1,100-mm press) briquettes. Table II presents the combustion test data for two chunk coals, six briquetted coal fines samples, and 1 cast coal fines sample. In addition to the emissions data for carbon dioxide, carbon monoxide, total hydrocarbons, sulfur dioxide, particulate matter, and oxides of nitrogen, this data also presents Equivalent Emissions (EE) and thermal efficiency for each fuel. Equivalent Emissions is a term defined by the Polish Ministry of Environmental Protection, Natural Resources, and Forestry. It 
is a weighted sum of the particulate matter (PM), carbon monoxide, sulfur dioxide, and oxides of nitrogen emissions:

$$
\mathrm{EE}=2.9 * \mathrm{PM}+0.5 * \mathrm{CO}+2.9 * \mathrm{NO}_{\mathrm{x}}+1.0 * \mathrm{SO}_{2}
$$

Thermal Efficiency $(\varepsilon)$ is the ratio, as percent, of the corrected heat to the input heat, where the input heat is the fuel mass times the heat capacity and the corrected heat is the input heat minus corrections for physical and chemical losses. The physical loss is the heat carried away by the stack gases. The chemical losses are the heat capacity of the unburnt carbon remaining on the grating, the carbon content of the ash found in the lower chamber of the stove, the carbon content of the particulate captured on the filter sample, the carbon monoxide emissions, and the total hydrocarbons emissions.

Integrated reactive gas emissions, particulate emissions, and thermal efficiencies are reported in Table II. Emission results are reported on an energy basis ( $g / \mathrm{MJ})$. The parenthetical expression in the second column of Table II describes the sample preparation. "W" and "Br" refer to Wujek and Brzeszcze coal, respectively. Briquettes prepared from Brzeszcze coal used a washed fine material. "Ch" refers to a chunk coal sample. "C", "G", and "K" refer to the three binder sources used in this work (Chrzanów, Gliwice, Kraków). Briquette samples include a number which is the percent binder in the formulation. "F" and "Co" refer to fine $(0$ to $2 \mathrm{~mm})$ and coarse $(0$ to $4 \mathrm{~mm})$ cuts of the washed Brzeszcze fines, respectively. "Ca" refers to a briquette prepared by casting in forms. Those briquetted samples not marked "Ca" were prepared on an $1,100-\mathrm{mm}$ ring roll press. The column headings "CO", "THC", "SO $2 ", " N O_{x}$ ", "Ms", "EE", and " $\varepsilon$ " refer to carbon monoxide, total hydrocarbons, sulfur dioxide, oxides of nitrogen, particulate matter emissions, Equivalent Emissions, and thermal efficiency, respectively. 
TABLE II. TILE STOVE COMBUSTION RESULTS FOR COAL AND BRIQUETTES

\begin{tabular}{|l|l|l|l|l|l|l|l||}
\hline Fuel Formulation & $\begin{array}{l}\mathrm{CO} \\
(\mathrm{g} / \mathrm{Mg})\end{array}$ & $\begin{array}{l}\mathrm{THC} \\
(\mathrm{g} / \mathrm{Mg})\end{array}$ & $\begin{array}{l}\mathrm{SO}_{2} \\
(\mathrm{~g} / \mathrm{Mg})\end{array}$ & $\begin{array}{l}\mathrm{NO}_{\mathrm{x}} \\
(\mathrm{g} / \mathrm{Mg})\end{array}$ & $\begin{array}{l}\mathrm{Ms} \\
(\mathrm{g} / \mathrm{Mg})\end{array}$ & $\begin{array}{l}\mathrm{EE} \\
(\mathrm{g} / \mathrm{Mg})\end{array}$ & $\varepsilon(\%)$ \\
\hline WU-PL $(\mathrm{W}, \mathrm{Ch})$ & 1.31 & 0.123 & 0.327 & 0.112 & 0.734 & 3.44 & 69.8 \\
\hline BRZE-1 (Br, Ch) & 0.997 & 0.14 & 0.245 & 0.139 & 0.781 & 3.43 & 70.7 \\
\hline 6BB $(\mathrm{Br}, \mathrm{K}, 10, \mathrm{~F})$ & 0.777 & 0.092 & 0.639 & 0.145 & 0.6 & 3.19 & 64.7 \\
\hline $8 \mathrm{BK}(\mathrm{Br}, \mathrm{K}, 14.3, \mathrm{~F})$ & 0.708 & 0.087 & 0.592 & 0.136 & 0.362 & 2.39 & 73.4 \\
\hline $8 \mathrm{BC}(\mathrm{Br}, \mathrm{C}, 14.3, \mathrm{Co})$ & 0.682 & 0.12 & 0.718 & 0.127 & 0.396 & 2.58 & 73 \\
\hline 9BK (Br, K, 14.3, Co) & 0.641 & 0.109 & 0.663 & 0.132 & 0.427 & 2.60 & 70 \\
\hline 1BOG (Br, G, 14.3, F) & 0.59 & 0.086 & 0.334 & 0.142 & 0.343 & 2.04 & 72.8 \\
\hline FXBC (Br, C, 14.3, F, Ca) & 0.79 & 0.072 & 0.598 & 0.08 & 0.359 & 2.27 & 75.8 \\
\hline
\end{tabular}

In examining the overall data set it may be noted that fuel sample $6 \mathrm{BB}$ contains the lowest binder content at 10 percent. Sample $6 \mathrm{BB}$ also has the lowest thermal efficiency and highest particulate matter emissions of the briquette samples. This high particulate matter emission sampler has the highest $\varepsilon$. Direct comparison of samples $6 \mathrm{BB}$ and $8 \mathrm{BK}$ suggests that the binder content may also play a role in carbon monoxide emissions. This data set, however, is not sufficient to prove this point. Samples $8 \mathrm{BC}$ and $9 \mathrm{BK}$ were prepared from 0 to $4 \mathrm{~mm}$ Brzeszcze fines while the remaining briquette samples were made with 0 to $2 \mathrm{~mm}$ fines. Samples $8 \mathrm{BC}$ and $9 \mathrm{BK}$ have higher hydrocarbon emissions than those briquettes prepared from the finer grade of coal fines. There may also be an effect on sulfur dioxide emissions but, if so, it is obscured by such other variables as the sulfur content of the fines and binder.

As Table II shows, four of the six briquette samples provide thermal efficiencies higher than the chunk coals. The cast sample, FXBC, may represent a special case. This sample provides a thermal efficiency of 75.8 percent. The briquette samples have equivalent emission values which are uniformly less than those for the two chunk coal samples. The best sample, $1 \mathrm{BOG}$, is 40 percent lower than the coal samples. 
The briquettes, as a class, provide reduced emissions of carbon monoxide, total hydrocarbons, and particulate matter relative to the chunk coal samples. Of those prepared on the ring roll press, sample 1BOG provides the best results for each of these pollutants. Relative to the average of the 2 chunk coals, it reduces carbon monoxide by 49 percent, hydrocarbons by 35 percent, and particulate matter by 55 percent.

The best hydrocarbon results are found for the cast sample, FXBC, which reduces total hydrocarbon emissions by 45 percent. Its particulate matter reduction, 53 percent, is second only to the $1 \mathrm{BOG}$ sample while reducing carbon monoxide by 32 percent. This cast sample is the only briquetted fuel which reduces oxides of nitrogen. A 53 percent reduction was observed for this sample. Samples prepared on the ring roll press display oxides of nitrogen emissions which are essentially identical to those from the chunk coal samples.

In general, the briquette samples are worse than the chunk coal samples in terms of sulfur dioxide emissions. Briquette sample $1 B O G$ is better than the other briquette samples in this respect with results which are basically equivalent to chunk coal samples. Sulfur dioxide emissions from sample $1 B O G$ are 17 percent greater than the average of these 2 coal samples and are only 2 percent greater than the Wujek coal sample.

Because briquettes are typically prepared from a source of fines which contains higher sulfur content than the equivalent chunk coal, higher sulfur dioxide emissions from briquettes may be an expected result. Fuel analysis of the washed Brzeszcze fines, 0.7 percent total sulfur, used in the briquette samples preparation confirmed this. This is more than twice the 0.3 percent sulfur content of the chunk Brzeszcze coal. It should also be noted that sample $1 B O G$ is the only briquette sample containing binder $\mathrm{G}$. This suggests the possibility that binders $\mathrm{C}$ and $\mathrm{K}$ are responsible for the higher sulfur dioxide emissions from the other 4 briquette samples. X-ray Fluorescence analysis was performed on binders $C$ and $K$. This confirmed the presence of minor concentrations of sulfur in 
these 2 binders. When the sulfur dioxide emissions were plotted as a function of the total sulfur content a linear relationship was easily observed.

\subsection{COMBUSTION TESTING AT INCO VERITAS}

Combustion testing was performed with the Clean Fuel at INCO Veritas in March/April 1995. The test fuel was manufactured by EMC at their Brikpol facility. Boilers numbers 1 and 2 were sampled using EPA method 5 and EPA modified method 5 during the combustion of the standard fuel, coke, and the Clean Fuel. The boilers at INCO Veritas (Eca IV), were a natural draft fixed grate units that were hand stoked. Details of the sampling protocols and proposed test matrix may be found in our fourth quarterly report, period of January 1, 1995 to March 31, 1995.

From a plant operations point of view, the Clean Fuel was not satisfactory. These boilers are operated to supply pressurized steam for the manufacturing processes. When using the standard fuel, coke, they maintain a steam pressure of approximately $0.04 \mathrm{MPa}$. The operators reported that they were unable to maintain this steam pressure when burning the briquetted fuel. Fluctuations of 0.01 to $0.02 \mathrm{MPa}$ were observed with the briquetted Clean Fuel.

\subsection{COMBUSTION TESTING AT PEC CHRZANÓW DISTRICT HEATING PLANT}

Combustion testing was performed with the Clean Fuel at PEC's Chrzanów district heating plant in May/June 1995. The test fuel was manufactured by EMC at their Brikpol facility. Testing was performed on 3 different forced draft travelling grate boilers ranging in size from 5.0 to $25 \mathrm{MW}$ rated output. A detailed description of the boilers, sampling protocols, and the test matrix may be found in our test plan, dated May 15, 1995.

From a plant operation point of view, the Clean Fuel was not satisfactory. Even though the Clean Fuel had a higher heat content, lower ash content, and lower moisture content than the current fuel; this product did not burn under these combustion conditions. This is attributed to the briquetted fuel's much lower surface area to fuel mass ratio. 
The standard fuel in use at these facilities is a coal fines material from the Ziemowit mine. Qualitatively, it may be described as having approximately 10 percent of its weight in the $>12 \mathrm{~mm}$ range and at least 50 percent in the 0 to $4 \mathrm{~mm}$ range. The finest grades of the feed fuel volatilize vigorously under these combustion conditions and ignite readily. The large size Clean Fuel used for these tests had a much lower rate of volatilization. It, therefore, did not ignite readily and combustion was less than half complete under even the slowest rate of grate travel. There was also a much lower pressure differential across the bed when briquettes were the feed fuel. 'Much of the air feed simply blew through the bed without contacting any of the fuel. The main effect of this was to simply cool the combustion zone and reduce the rate of combustion even further. All of these observations are in line with operator comments. They mentioned that this was exactly what they saw some years ago when they attempted to use chunk coal as the feed fuel.

Based upon the preliminary experiments the test plan was modified to incorporate testing at the 3 boilers utilizing 5 fuels:

- Ziemowit fines (the regular fuel at these boilers)

- Brzeszcze fines (same as used in the production of the Clean Fuel)

- Crushed Clean Fuel (in an attempt to reduce the size)

- Brzeszcze fines with crushed Clean Fuel

- Ziemowit fines with crushed Clean Fuel

In summary, our result show that the load, as a percent of rated load, is the most important factor in the emissions from these units. The load is a more important factor than the fuel type or even the boiler. This is entirely true for the reactive gas measurements (sulfur dioxide, nitrogen oxides, carbon monoxide, and total hydrocarbons) and is mostly true for particulate matter. For particulate matter, calculated as pounds of particulate matter per MW of thermal energy, data from the 5 and $10 \mathrm{MW}$ units fall within the same cluster while the data from the $25 \mathrm{MW}$ unit is at distinctly lower level. 


\subsection{CLEAN FUEL PRODUCTION AT BRIKPOL}

Quantity production of Clean Fuel was accomplished at EMC's Brikpol facility. Based upon the Academy's testing results, EMC was directed to prepare Clean Fuel utilizing the following recipe:

- 0 to $2 \mathrm{~mm}$ washed Breszcze coal fines

- Chrzanów sourced binder

- 14.3 percent binder content

- Wet mixing

- Moisture content of 10 to 12 percent

- 1,100-mm ring roll press formation

- Dried after formation

There was a delay in production due to late delivery of washed fines. EMC also found it necessary to make a substitution on the binder sourcing; Gliwice sourced binder was actually used for production. They found that their mixing equipment was unable to handle the chunky nature of the Chrzanów material; the mixing shaft sheared and had to be rewelded. The Gliwice material was found to be available in powder form and proved to be entirely satisfactory. Once these problems were overcome, production proceeded without delay.

\subsection{HEATING SEASON PRODUCTION TO SUPPORT THE WITH-PRODUCT MARKET TESTING}

As discussed above Clean Fuel production was performed at EMC's Brikpol facility. In addition to providing briquettes for testing at INCO and PEC-Chrzanów, Clean Fuel were also manufactured for use in the with-product market test. These Clean Fuel was delivered to Kraków at the end of the 1994 heating season in time for the with-product market test to be performed.

\subsection{TCLP TESTING OF COMBUSTION RESIDUES}

Residues from the tile stove tests and PEC boilers were submitted to AGH for TCLP testing. These results have not been received and are not expected. 


\section{SECTION 8.0}

\section{CONCLUSIONS}

1. Phase I technical goals were met. Most notably the testing of Clean Fuel in ceramic home heating stoves, hand stoked boilers, and small industrial boilers was accomplished.

2. Clean Fuel formulations were defined that assured sufficient mechanical strength while yielding low emissions of particulate matter and gaseous pollutants.

3. Relative to chunk coal, particulate matter, total hydrocarbons, and carbon monoxide emissions were reduced by 56,39 , and 41 percent, respectively when using the Clean Fuel in a ceramic home heating stove. 